\title{
The contribution of Italian cultural blogs to heritage valorization
}

\author{
Francesca Magno - Cristina Bettinelli - Mara Bergamaschi
}

\begin{abstract}
Purpose of the paper: Available studies have often reported a gap between the supply and the (potential) demand for cultural products. Ineffective communication is often mentioned as one of the main reasons for this mismatch: such communication is unidirectional and uses a technical language which is understandable only by a niche public. The purpose of this study is to investigate whether cultural blogs (in particular organizationally unaffiliated blogs acting as intermediaries between the suppliers and the consumers of cultural products) are able to assist their readers to decide which cultural products to consume. A theoretical model to describe this effect is developed and tested.

Methodology: This research is based on data collected through a survey among the readers of two Italian cultural blogs. Structural equation modelling is used to analyse the data.

Findings: The findings demonstrate that cultural blogs influence their readers' selection and consumption of cultural products. The results also show that this effect is the result of both utilitarian and hedonic benefits provided to the reader by the cultural blog.

Research limits: The analysis is based on data collected among the readers of only two Italian cultural blogs. In addition, the sample size is limited. Further studies are needed to generalize the results.

Practical implications: The study has implications for both cultural bloggers and the organizations supplying cultural products (such as museums). For cultural bloggers, the analysis shows the importance of balancing the informative contents of their blogs with enjoyment opportunities for the readers. In addition, this study suggests that the suppliers of cultural goods should cooperate with cultural bloggers because if their products are reviewed in those blogs they will have more chances of being selected by readers.

Originality of the paper: To our knowledge, this is the first national and international scientific study to empirically test the effects of cultural blogs on readers' behaviour.
\end{abstract}

Key words: cultural blogs; blogs; cultural products; social media.

\section{Introduction}

Consumers of cultural products can't base their purchasing and consumption decisions only on the utilitarian value of the offering, which is actually very low (Peltoniemi, 2015). On the contrary they need to appreciate 
Sinergie Vol. 34, N. 99, 2016

the aesthetic (Hirsch, 1972), symbolic (DeFillippi et al., 2007; Markusen et al., 2008), social display (Bourdieu, 1984) and experiential value of those cultural products (Peltoniemi, 2015). Hence communication plays a pivotal role in helping potential consumers to understand the intrinsic value and select among the large variety of available cultural products (e.g., exhibitions to visit, books to read, etc.) (Peltoniemi, 2015).

However, communication of cultural products is often ineffective because it is unidirectional and uses a technical language which is understandable only by a niche public (Solima, 2008). This makes such communication available only to qualified connoisseurs, experts and enthusiasts of culture (Barile and Saviano, 2012).

Some authors have suggested that blogs may contribute to make the communication of cultural products more effective by creating and diffusing knowledge, thus playing an important intermediary role between suppliers and consumers (Solima, 2010). Since their emergence in the late '90s, the importance of blogs has grown exponentially (Dearstyne, 2005), covering a wide range of topics, including sports, automotive, fashion and many others (Cosenza et al., 2015; Shiau and Luo, 2013). In particular, following Throsby's conceptualization of culture (1994), here we define cultural blogs as those covering a very eclectic area mixing aesthetics, history, philosophy, sociology, politics and many other disciplines.

Blogs are "diary-style web sites" (Johnson and Kaye, 2004), which allow bloggers to write opinions, reviews, ideas, personal stories, emotions, etc. (Chau and $\mathrm{Xu}, 2012$ ). Several studies have shown that blogs, compared to other media, are more dynamic and are perceived as more reliable by users (Cosenza et al., 2015). Therefore, they may significantly influence readers' behavior. For example, in a typical hedonic field such as fashion, Halvorsen et al. (2013) have demonstrated that fashion blogs can play a role in affecting consumer behaviors. However, this effect still needs to be strongly proved (Cosenza et al., 2015).

Drawing on these premises, the aim of this paper is to investigate whether cultural blogs are able to influence readers' decisions about which cultural products to consume. For this purpose, we suggest and test a model to explain cultural blogs' influence on readers' behavior. The model draws on the distinction between utilitarian and hedonic beliefs (Homer, 2008; Voss et al., 2003), thus hypothesizing that readers' attitudes toward cultural blogs are driven both by utilitarian beliefs (e.g., readers' perception about the accurateness of the information posted in the blog) and by hedonic beliefs (e.g., readers' enjoyment with the blog). In turn, we hypothesize the existence of a positive and strong relationship between the attitude towards the blog and behaviors. To test our model, we present the results of a survey that involved the users of two Italian cultural blogs.

The results of this paper may have relevant implications for both theory and practice. As regards theory, they may contribute to close the gap about the influence of cultural blogs on readers' behaviors. From a managerial perspective, they may provide bloggers with evidence about the effect of blogs on readers and with guidance about the hedonic or utilitarian aspects of the blog that need to be emphasized. They may also indicate to 
a supplier of cultural goods the extent to which it is important to cooperate with cultural bloggers.

The remainder of this paper is articulated as follows: first, we provide a review of the literature by underlining the importance of communication aimed at supporting the consumption of cultural products and the limits of traditional practices, and by highlighting the opportunity to extend the potential of social media, and in particular of blogs, to the cultural context. Second, we provide theoretical evidence to develop research hypotheses. Third, we introduce the methodology, including information on the data gathering process, the measure development, and the data analysis procedures. Fourth, we present the results of the survey and discuss the study's theoretical contributions, managerial implications, and potential directions for further research.

\section{Literature review and hypotheses}

Cultural products have some distinctive features (Peltoniemi, 2015) that emphasize the importance of communicating them effectively to current and potential consumers (Aiello, 2014).

First, cultural products (i.e. cultural goods and services (Rispoli and Tamma, 1992) embracing a range of issues in philosophy, aesthetics, history, sociology, politics, and many other disciplines (Throsby, 1994)) are more abstract, have less functional utility and are experienced more subjectively than all other products (Bourgeon-Renault, 2000). Hence selecting which cultural products to consume and being able to derive benefits from their consumption may be quite complex for consumers (Brito and Barros, 2005). In particular, consumers have to engage in a cultivation-of-taste process to select and enjoy these products (Brito and Barros, 2005). The accumulation of culture-related knowledge and experience is therefore particularly important (Stigler and Becker, 1977) and communication has a pivotal role for this purpose.

Second, several studies have demonstrated that the consumption of cultural products is strongly correlated with customers' level of education (Throsby, 1994). In addition, older people generally show higher levels of cultural consumption (Katz-Gerro, 2011). Finally, cultural products consumption is related to specific consumers' lifestyle, which are the representation of groupings or 'tribes' that share a style of behavior, taste, and habits (Katz-Gerro, 2011). In sum, available analyses show that a large portion of the population is not involved in the consumption of cultural products, which often attracts only qualified connoisseurs, experts and enthusiasts (Barile and Saviano, 2012). Communicating cultural products in a way that is accessible to a larger public is therefore fundamental.

Given the importance of communication to support the consumption of cultural products, but also considering the limited effectiveness of traditional practices (Aiello, 2014), several academicians, organizations and practitioners have started to explore the potential of social media in the cultural context (Solima, 2010). In this paper we particularly focus on the role of blogs, which represent informal channels of communication
Francesca Magno Cristina Bettinelli

The contribution of Italian

cultural blogs to heritage valorization 
sinergie Vol. 34, N. 99, 2016

(Kulmala et al., 2013) and, differently from most of cultural organizations' communications traditional approach, are not unidirectional but interactive (Solima, 2008).

Blogs are classified as social media and user-generated content (Cosenza et al., 2015) and "are diary-style websites that generally offer observations and news listed chronologically" (Johnson and Kaye, 2004, p. 622). Differently from traditional media, blogs are two-way communication channels, where the blogger and her/his readers have the opportunity to interact (Bernoff and $\mathrm{Li}, 2008$ ). Blogs can be divided into personal (organizationally unaffiliated) blogs and organization-sponsored blogs (such as a museum-sponsored blog) (Sweetser and Metzgar, 2007). In this study we focus on organizationally unaffiliated blogs, i.e. blogs which act as intermediaries between the suppliers and the (actual and potential) consumers of cultural products. In the case of cultural products, consumers may use these blogs' reviews to complement or to substitute professional evaluations (Peltoniemi, 2015). Previous research suggests that consumers consider personal blogs as more credible than other online and offline sources of information (Johnson and Kaye, 2009) and therefore such blogs may influence consumers' purchase behavior (Cosenza et al., 2015). In addition, several studies (e.g., Lu and Lin, 2002) have demonstrated that consumer beliefs about a website's content have an impact on consumers' attitude towards the same site. In turn, attitude towards a website has been found to be an important predictor of consumer behavior (Casaló et al., 2010; Gordon and Anand, 2000). Nonetheless, evidence concerning the effects of blogs on blog readers' actual behaviors remains scarce (Cosenza et al., 2015; Halvorsen et al., 2013).

Drawing on these premises, this paper explores whether cultural blogs are able to influence blog readers' behavior regarding the consumption of cultural goods. In particular, we develop and test a model which states that blog readers' behavior (in particular, the decision about which cultural products to consume) is the result of her/his attitude towards the blog, which is in turn the result of his/her beliefs related to the blog (fig 1).

In particular, drawing on previous studies demonstrating the separation

between utilitarian and hedonic beliefs (Batra and Ahtola, 1991; Batra and Homer, 2004; Homer, 2008; Homer, 2006) and their impact on attitudes (Voss et al., 2003), we state that readers' attitudes toward the blog are driven by both utilitarian and hedonic beliefs. Utilitarian beliefs are associations that the consumers make with the instrumental and functional benefits provided by an evaluated object (i.e., the blog in our study), while hedonic beliefs are associations with the affective and experiential gratification benefits provided by an evaluated object (Batra and Ahtola, 1991). 


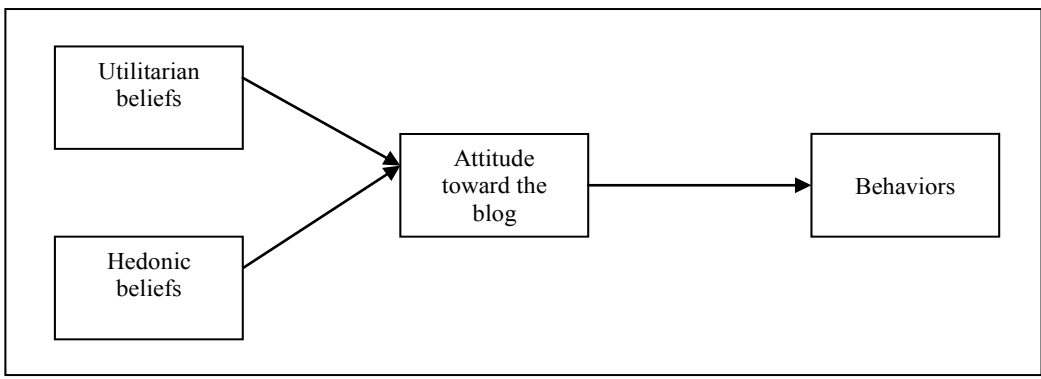

cultural blogs to heritage

valorization

Source: our analysis

Over the past, scholars have directed attention to the fact that consumers are feelers as well as thinkers and doers (Addis and Holbrook, 2001). In this respect, utilitarian and hedonic beliefs seem to play a relevant role in explaining the formation of attitudes and behaviors. As regards utilitarian benefits, blogs contain detailed and updated information about a specific topic, which may enhance the reader's performance in terms of effectiveness (Hsu and Lin, 2008) and affect attitude formation (Sookeun and Feinberg, 2007). For example, research has shown that utilitarian beliefs are important for explaining consumers' attitudes towards channel switching (Pookulangara et al., 2011), and internet messaging (Premkumar et al., 2008). Another example refers to a recent study by Bilgihan et al., (2016) on tourists using online social networks when making travel decisions. Also in this case, utilitarian beliefs referred to the online social network emerged to positively influence relevant aspects related to attitudes such as belief in the integrity of the online social network (Bilgihan et al., 2016). These examples offer empirical support to the idea that utilitarian beliefs play a significant and positive role in explaining readers' attitude towards the blog.

Nonetheless, while many studies have applied this framework to the online context, only a few contributions have suggested that blogs provide readers with both utilitarian and hedonic benefits. In general, through blogs, readers have the possibility to satisfy different needs and wants (Park et al., 2010) such as searching for information, entertainment and personal gratification - which can be classified as either utilitarian or hedonic. For example, Chiang and Hsieh (2011) emphasize the presence of four motivations for reading a blog, one of which is utilitarian (information seeking) and three of which are hedonic (interpersonal exchange, entertainment and following trends).

In particular, Pöyry et al. (2013) highlighted that, through blogs, readers try to reach functional objectives, i.e. obtain useful information. Despite the mare magnum of information available on the web, blogs enable readers to find updated and useful information about a topic of interest (Bagozzi and Dholakia, 2002). In the case of a cultural blog, the information published in the blog about specific cultural products may help the reader to evaluate which cultural products are best for her/him. Thus, the highquality informative content of a blog will provide the reader with significant utilitarian benefits. Therefore, we state that: 
sinergie Vol. 34, N. 99, 2016

$\mathrm{H} 1$ : In the case of a cultural blog, there is a positive relationship between utilitarian beliefs and attitude towards the blog.

Similarly, previous research has showed that internet-related and blog-participating activities offer hedonic benefits to consumers in terms of enjoyment (Hsu and Lin, 2008; Shiau and Luo, 2013). Hedonic value generally reflects the worth found in the experience itself and embodies aspects of fantasy, the emotive dimensions of the consumed experience, playfulness, and fun (Babin and Attaway, 2000; Childers et al., 2002; Noble et al., 2005). Additionally, hedonic values describe experiential benefits such as escapism, relaxation and entertainment (Overby and Lee, 2006). Therefore, it is likely that this type of belief is also particularly relevant in the context of cultural blogs. For cultural blogs' readers, hedonic benefits are particularly important given the high aesthetic and symbolic nature of culture and cultural products (Peltoniemi, 2015). Hence we state that:

$\mathrm{H} 2$ : In the case of a cultural blog, there is a positive relationship between hedonic beliefs and attitude towards the blog.

Finally, to develop the third hypothesis we relied on previous studies highlighting the direct effect of online product recommendations on consumers' purchasing decisions (Ho and Bodoff, 2014). In particular, Ho and Bodoff (2014) demonstrated that when a web personalization agent (i.e. the blog in this paper) selects and advertises a small set of recommendations that match a person's interests, the person's attitude toward the personalization agent significantly influences her/his decision to choose one of the recommendations as the final choice. This relationship is also consistent with the well-established literature about behavioral compliance, showing that when a consumer perceives the source of information as credible, s/he will be more likely to follow the advice and recommendations provided by that source (Pornpitakpan, 2004). Following this tradition, we posit that:

H3: There is a positive relationship between a reader's attitude towards a cultural blog and her/his consumption behaviors (i.e., the decision about which cultural products to consume).

\section{Method}

To test the hypotheses, an online survey was conducted in March 2015 among the readers of two Italian cultural blogs. These two blogs are in the top ten positions of the Italian cultural blogs ranking released by Teads (which is a reliable consulting firm specialized in online activities all over the world). This ranking is based on different criteria and is able to register the popularity of a blog. In particular, we contacted the bloggers managing the blogs in the top ten positions of the ranking to obtain their consent to publish a post and a link to our questionnaire on their blogs. Two of them agreed. 
The first blog was created in 2011 and is managed by a group of art historians. In the presentation of their blog they state the following: "We needed a communication tool which was simpler, more straightforward and more flexible than an online magazine. We feel a very urgent need to reconcile the study-related and communication-related potential of digital technologies for research, the so-called digital humanities, and to be on the net with our point of view and our training. This need is even more evident when we consider, especially in the Anglo-Saxon world, the disclosure of new perspectives of art history within the Internet and digital publishing".

The second blog was created in 2012 and covers the following topics: arts, visual arts, humanities, culture and curiosities.

In general, both blogs publish posts which are short, full of pictures and contain detailed information (fig. 2 shows one of the posts that were published in the blogs participating in this study).

Fig. 2: An example of the posts published in the blogs participating in this study

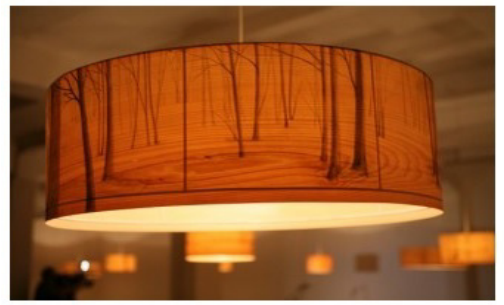

MOSTRE DI MARZO: 7 CONSIGLI PER VOI

Cosa c'è da vedere a Marzo in Italia? Ecco una

selezione di 6 mostre in gallerie e spazi

indipendenti che dovreste assolutamente

vedere

LEGGI TUTTO
Source: Blogs participating in this study

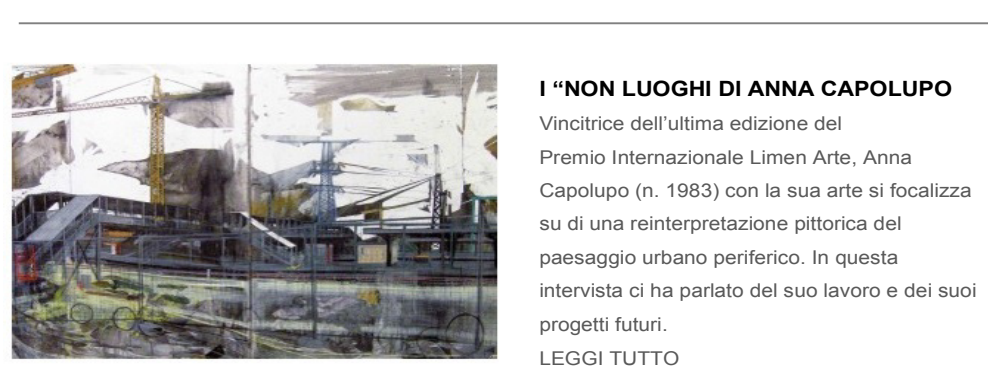

Francesca Magno

(r)

The contribution of Italian

cultural blogs to heritage valorization

The two blogs published a post with the link to our questionnaire in March 2015 (fig. 3).

The questionnaire was organized into three sections: one was related to the beliefs of the readers about the cultural blog; the second section was about the habits and the behavior of the readers and the final section investigated other aspects that were not related to the aim of this research. 


\section{sinergie}

Vol. 34, N. 99, 2016

Fig. 3: The post with the link to our questionnaire published by one of the two blogs

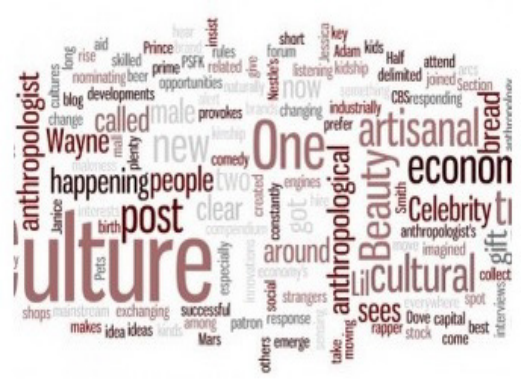

Source: Blogs participating in this study
CULTURA E WEB: DITECI LA VOSTRA!

Partecipa all'indagine su Cultura e Web

dell'Università di Bergamo per capire che

ruolo i "nuovi" media possono avere nella

diffusione della cultura. Compila ora il

questionario!

LEGGI TUTTO

Most of the items used to measure the main constructs (table 1) were taken from previous studies, with some adaptations to the specific research setting. Hedonic beliefs included four items ( $1=$ strongly disagree; $7=$ strongly agree), while utilitarian beliefs were measured by three items. Both constructs were derived from the work of Hsu and Lin (2008). Attitude towards the blog was measured by two items ( $1=$ strongly disagree; $7=$ strongly agree) adapted from Shiau and Luo (2013). Finally, the two items developed by Li et al. (2008) were adapted and used to register readers' behavior ( $1=$ strongly disagree; $7=$ strongly agree). The measurement and structural models were then tested using the structural equation modelling technique. In particular, it was possible to assess the validity of the scales in the specific research setting.

\section{Results}

Up to now, 117 responses have been collected, however, 10 of them have been excluded due to incomplete answers. Therefore we have obtained 107 usable answers (50 from the first blog and 57 form the second blog). Respondents are mainly female (58.5\%), have a medium-to-high level of education (79.5\% have a bachelor's degree or post-graduate degree) and an average age of 34 years. As regards their occupation, $27.1 \%$ of participants are employees, $5.6 \%$ are students, $4.7 \%$ are housewives, $49.5 \%$ are selfemployed people, while $13.1 \%$ are unemployed. As regards the attachment to the blog, $49.5 \%$ of respondents have been following the blog for more than one year, while $44 \%$ for more than one month but less than a year and only the $6.5 \%$ for less than one month.

Before estimating the structural model to test the suggested hypotheses, a confirmatory factor analysis (CFA) was conducted to assess constructs' convergent and discriminant validity. The CFA's overall goodness of fit is satisfactory (Kaplan, 2009) with Chi-square $(\mathrm{df}=39)=72.98, \mathrm{p}<0.01$; $\mathrm{CFI}=0.96$ and RMSEA $=0.09$. Table 1 shows the details of the measurement model. Since the CFA confirmed the validity and reliability of the measurement model, we were able to use the corresponding latent variables to estimate the structural equation model. 
Tab. 1: The measurement model

\begin{tabular}{|c|c|c|c|c|c|}
\hline Construct & Item & Mean & S.D. & C.R. & $\begin{array}{c}\text { Factor } \\
\text { Loading }\end{array}$ \\
\hline \multirow{4}{*}{$\begin{array}{l}\text { Hedonic } \\
\text { Beliefs }\end{array}$} & $\begin{array}{l}\text { HB_1 - Spending time on this blog is } \\
\text { relaxing }\end{array}$ & 4.85 & 1.69 & l & 0.96 \\
\hline & HB_2 - I enjoy following this blog & 4.72 & 1.67 & 16.90 & 0.93 \\
\hline & $\begin{array}{l}\text { HB_3 - I enjoy posting my comments on } \\
\text { this blog }\end{array}$ & 3.22 & 1.88 & 7.38 & 0.61 \\
\hline & $\begin{array}{l}\text { HB_4 - Through this blog I travel with my } \\
\text { imagination }\end{array}$ & 4.51 & 1.89 & 8.67 & 0.67 \\
\hline \multirow{3}{*}{$\begin{array}{l}\text { Utilitarian } \\
\text { Beliefs }\end{array}$} & $\begin{array}{l}\text { UB_1 - The information provided by this } \\
\text { blog is accurate }\end{array}$ & 5.97 & 1.32 & 1 & 0.90 \\
\hline & $\begin{array}{l}\text { UB_2 - The information and suggestions } \\
\text { published in this blog are reliable }\end{array}$ & 6.12 & 1.19 & 15.72 & 0.94 \\
\hline & $\begin{array}{l}\text { UB_3 - The contents of this blog are } \\
\text { updated }\end{array}$ & 6.04 & 1.25 & 14.21 & 0.90 \\
\hline \multirow{2}{*}{$\begin{array}{l}\text { Attitude } \\
\text { toward the } \\
\text { Blog }\end{array}$} & ATTB_1 - This blog is valuable for me & 4.77 & 1.75 & 10.90 & 0.86 \\
\hline & $\begin{array}{l}\text { ATTB_2 - I am very attached to this } \\
\text { blog }\end{array}$ & 4.69 & 1.61 & I & 0.85 \\
\hline \multirow[b]{2}{*}{ Behavior } & $\begin{array}{l}\text { B_1 - On many occasions I followed the } \\
\text { advice posted on this blog }\end{array}$ & 4.81 & 1.66 & 10.97 & 0.85 \\
\hline & $\begin{array}{l}\text { B_2 - I often decide what cultural events } \\
\text { to attend, books to read, etc., based on the } \\
\text { advice of this blog }\end{array}$ & 5.42 & 1.40 & I & 0.89 \\
\hline
\end{tabular}

Source: our analysis

The structural model (fig. 4 and table 2) shows an overall good fit, with Chi-square $(\mathrm{df}=39)=63.84, \mathrm{p}<0.01 ; \mathrm{CFI}=0.97$ and RMSEA $=0.07$. As Table 1 shows, the utilitarian and hedonic beliefs are two relevant yet distinct concepts, a result in line with previous empirical literature (Eggert and Ulaga, 2002).

As regards the suggested relationships among the variables, data highlight that all the hypotheses are supported. In particular, both hedonic beliefs $(\beta=.37 ; \mathrm{p}<0.01)$ and utilitarian beliefs $(\beta=.56 ; \mathrm{p}<0.01)$ are significant antecedents of attitude towards the blog, thus supporting hypotheses 1 and 2 . In addition, attitude towards the blog has a significant and strong influence on readers' behavior $(\beta=.91 ; \mathrm{p}<0.01)$, supporting hypothesis 3 .
Francesca Magno Cristina Bettinelli

Mara Bergamaschi

The contribution of Italian

cultural blogs to heritage valorization 
sinergie Vol. 34, N. 99, 2016
Fig. 4: The structural model

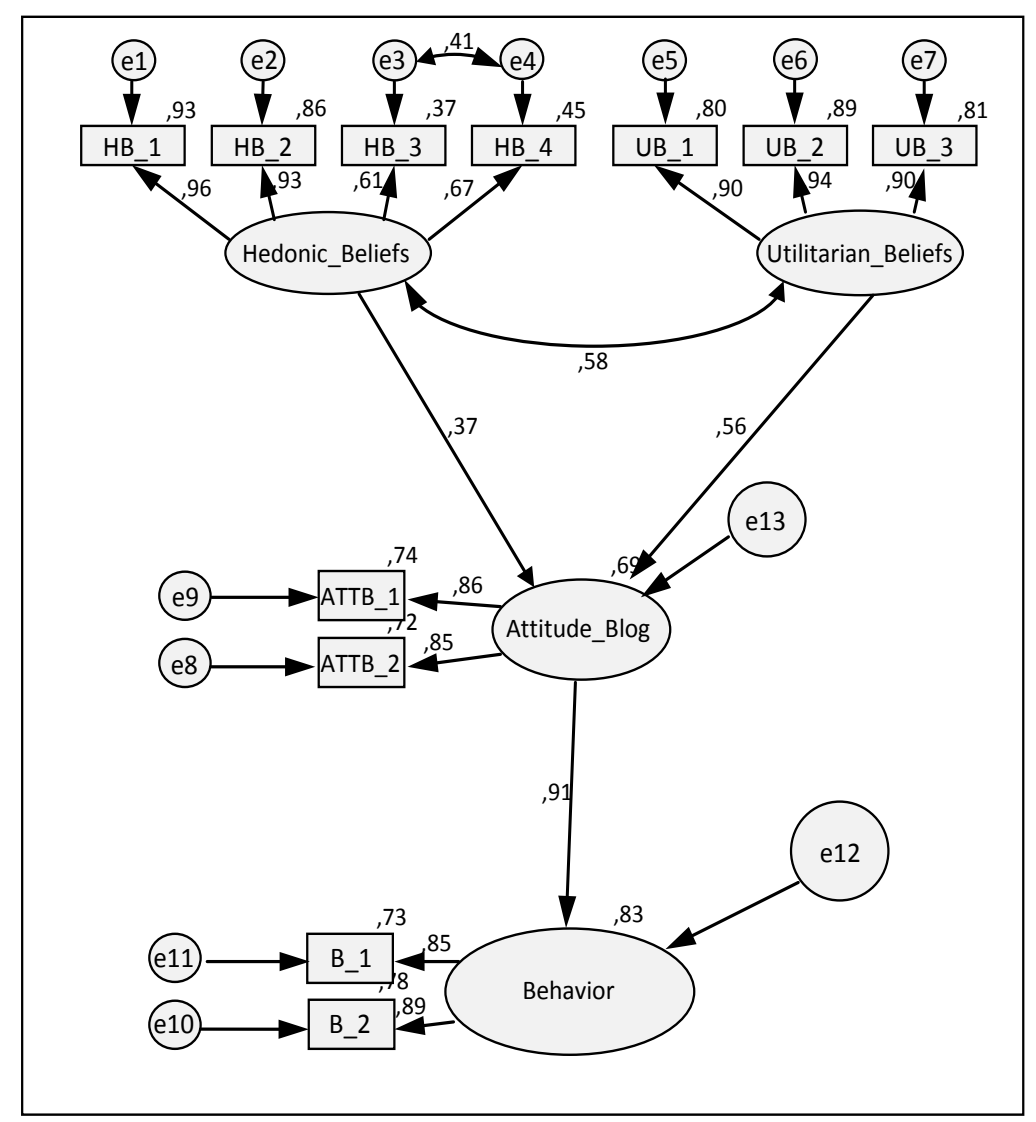

Source: our analysis

Tab. 2: The structural model

\begin{tabular}{|l|c|c|c|}
\hline & \multicolumn{3}{|c|}{ Estimated Model } \\
\hline & $\begin{array}{c}\text { Unst. } \\
\text { Coeff. }\end{array}$ & SE & $\begin{array}{c}\text { Std. } \\
\text { Coeff. }\end{array}$ \\
\hline H1: Hedonic beliefs $\rightarrow$ Attitude towards the blog & 0.314 & 0.074 & 0.373 \\
\hline H2: Utilitarian beliefs $\rightarrow$ Attitude towards the blog & 0.647 & 0.108 & 0.560 \\
\hline H3: Attitude towards the blog $\rightarrow$ Behavior & 0.829 & 0.084 & 0.913 \\
\hline Model fit & $63.84, \mathrm{df}=39, \mathrm{p}<0.01$ \\
\hline Chi-square & 0.07 \\
\hline RMSEA & 0.97 \\
\hline CFI & \multicolumn{4}{|l}{} \\
\hline
\end{tabular}

Source: our analysis 


\section{Discussion and conclusions}

This study extends the current literature that demonstrates the separation between utilitarian and hedonic beliefs (Batra and Ahtola, 1991; Batra and Homer, 2004; Homer, 2008; Homer, 2006) and their impact on attitudes (Voss et al., 2003), additionally, it reveals the existence of a direct relationship between attitudes and consumers' behavior in the context of cultural blogs.

Moreover, by focusing on cultural blogs, this study contributes to the empirical body of research on the effectiveness of cultural products' communication. By focusing on this context, the study has been designed to provide answers to if and how cultural blogs can influence their readers' behavior by acting as (informative) intermediaries between the suppliers and the (potential) consumers of cultural products. In fact, in the cultural context consumers who are not experts need to rely on intermediaries to accumulate culture-related knowledge and experience which is pivotal to appreciate cultural products and select among them. The findings of this study demonstrate that cultural blogs can effectively play this role of intermediary. In detail, the analysis emphasizes that cultural blogs influence consumer behavior regarding the consumption of cultural products and that this influence depends on consumer attitude towards the blog. Therefore, it is fundamental to understand how consumers form their attitudes towards the blog.

The results demonstrate that such attitudes derive from both the perceived utilitarian value and from the perceived hedonic value of the blog. In detail, the utilitarian value is related to the updated and accurate information provided by the blog while the hedonic value is connected to enjoyment and entertainment with the cultural blog. In turn, when consumers develop positive attitudes towards the cultural blog, they will then strongly take the blog's suggestions into consideration when they have to select cultural products to consume. This means that the cultural blog acts as a web personalization agent that is capable of influencing consumers' final decision about the consumption of cultural products.

This paper enriches available knowledge about the impact of social media in the cultural context by demonstrating the effectiveness of cultural blogs.

In a broader sense, the findings also provide empirical support for Franch's (2010) idea that technological innovation should contribute to the diffusion of culture. This may also contribute to lower the age of consumers of cultural products. On this point, it may be interesting to note that the average age of the blog readers participating in this study was 34 years, which is much lower compared to that of "regular" cultural product consumers (Katz-Gerro, 2011).

Moreover, the results of this research have practical implications for both suppliers of cultural products (such as museums or other cultural institutions) and cultural bloggers. For suppliers, cultural blogs may represent an effective communication tool, requiring a low level of investment. In particular, focusing on enhancing the level of collaboration with cultural bloggers may increase the probability that reviews of their products will be 
sinergie Vol. 34, N. 99, 2016

posted by them with limited marketing expenditure. In fact, the analysis shows that readers are likely to consume the cultural products reviewed on the blog. In addition, suppliers have the opportunity to expand their audience beyond their current public, by reaching younger people.

For cultural bloggers, the analysis emphasizes the importance of balancing utilitarian and hedonic benefits. This means that designing a cultural blog that focuses only on high-quality informative contents (i.e., utilitarian benefits) may not be enough to stimulate strong positive attitudes towards the blog among its readers. The blog should also satisfy the need for enjoyment, relax and gratification.

In sum, it is important to create a compelling online environment based on both utilitarian and hedonic aspects.

This study presents several limitations as well. First, the analysis is based on data collected from only two Italian cultural blogs. As mentioned before, culture is a very eclectic area, so analyzing more blogs related to different aspects of culture may corroborate our findings. In particular, as this is an exploratory study and given the richness of this topic which is still under investigation, other variables should be considered in the future to enrich our understanding of this issue. Moreover, the sample size is limited. Finally, this paper has only considered organizationally unaffiliated blogs, which are particularly interesting given their intermediary role between suppliers and consumers. Future studies should also extend the analysis to organization-sponsored blogs (such as museums-sponsored blogs) to appreciate the overall potential of blogs in the cultural field.

\section{References}

ADDIS M., HOLBROOK M.B. (2001), "On the conceptual link between mass customisation and experiential consumption: an explosion of subjectivity", Journal of consumer behaviour, vol. 1, n. 1, pp. 50-66.

AIELLO L. (Ed.) (2014), Handbook of Research on Management of Cultural Products: E-Relationship Marketing and Accessibility Perspectives: E-Relationship Marketing and Accessibility Perspectives, IGI Global, New York.

BABIN B.J., ATTAWAY J.S. (2000), "Atmospheric affect as a tool for creating value and gaining share of customer", Journal of Business research, vol. 49, n. 2, pp. 91-99.

BAGOZZI R.P., DHOLAKIA U.M. (2002), "Intentional social action in virtual communities", Journal of interactive marketing, vol. 16, n. 2, pp. 2-21.

BARILE S., SAVIANO M. (2012), "Dalla Gestione del Patrimonio di Beni Culturali al Governo del Sistema dei Beni Culturali”, in Golinelli G.M. (Ed.) Patrimonio culturale e creazione di valore, Verso nuovi percorsi, Cedam, Padova, pp. 97-148.

BATRA R., AHTOLA O.T. (1991), "Measuring the Hedonic and Utilitarian Sources of Consumer Attitudes", Marketing Letters, vol. 2, n. 2, pp. 159-170.

BATRA R., HOMER P.M. (2004), “The situational impact of brand image beliefs", Journal of Consumer Psychology, vol. 14, n. 3, pp. 318-330.

BERNOFF J., LI C. (2008), "Harnessing the power of the oh-so-social web”, MIT Sloan Management Review, vol. 49, n. 3, pp. 36. 
BILGIHAN A., BARREDA A., OKUMUS F., NUSAIR K. (2016), "Consumer perception of knowledge-sharing in travel-related Online Social Networks", Tourism Management, vol. 52, February, pp. 287-296.

BOURDIEU P. (1984), Distinction: A social critique of the judgement of taste, Harvard University Press, Cambridge, MA.

BOURGEON-RENAULT D. (2000), "Evaluating consumer behaviour in the field of arts and culture marketing", International Journal of Arts Management, vol. 3, n. 1, pp. 4-18.

BRITO P., BARROS C. (2005), "Learning-by-Consuming and the Dynamics of the Demand and Prices of Cultural Goods", Journal of Cultural Economics, vol. 29, n. 2, pp. 83-106.

CASALÓ L.V., FLAVIÁN C., GUINALÍU M. (2010), "Determinants of the intention to participate in firm-hosted online travel communities and effects on consumer behavioral intentions", Tourism Management, vol. 31, n. 6, pp. 898-911.

CHAU M., XU J. (2012), "Business intelligence in blogs: Understanding consumer interactions and communities", MIS quarterly, vol. 36, n. 4, pp. 1189-1216.

CHIANG I., HSIEH C.H. (2011), "Exploring the impacts of blog marketing on consumer", Social Behavior and Personality: an international journal, vol. 39, n. 9, pp. 1245-1250.

CHILDERS T.L., CARR C.L., PECK J., CARSON S. (2002), "Hedonic and utilitarian motivations for online retail shopping behavior", Journal of retailing, vol. 77, n. 4, pp. 511-535.

COSENZA T.R., SOLOMON M.R., KWON W.K. (2015), "Credibility in the blogosphere: A study of measurement and influence of wine blogs as an information source", Journal of Consumer Behaviour, vol. 14, n. 2, pp. 71-91.

DEARSTYNE B.W. (2005), "Blogs: the new information revolution?", Information Management Journal, vol. 39, n. 5, pp. 38-44.

DEFILLIPPI R., GRABHER G., JONES C. (2007), "Introduction to paradoxes of creativity: managerial and organizational challenges in the cultural economy", Journal of Organizational Behavior, vol. 28, n. 5, pp. 511-521.

EGGERT A., ULAGA W. (2002), "Customer perceived value: a substitute for satisfaction in business markets?", Journal of Business and Industrial Marketing, vol. 17, n. 2/3, pp. 107-118.

FRANCH M. (2010), "Le frontiere manageriali per la valorizzazione della cultura e dell'arte”, Sinergie n. 82, pp. 95-107.

GORDON B., ANAND K. (2000), "Web commercials and advertising hierarchy-ofeffects", Journal of Advertising Research, vol. 40, n. 1, pp. 35-42.

HALVORSEN K., HOFFMANN J., COSTE-MANIÈRE I., STANKEVICIUTE R. (2013), "Can fashion blogs function as a marketing tool to influence consumer behavior? Evidence from Norway", Journal of Global Fashion Marketing, vol. 4, n. 3, pp. 211-224.

HIRSCH P.M. (1972), "Processing fads and fashions: An organization-set analysis of cultural industry systems", American Journal of Sociology, vol. 77, n. 4, pp. 639-659.

HO S.Y., BODOFF D. (2014), "The effects of web personalization on user attitude and behavior: an integration of the elaboration likelihood model and consumer search theory", MIS quarterly, vol. 38, n. 2, pp. 497-520. 
sinergie Vol. 34, N. 99, 2016

HOMER P.M. (2006), "Relationships among ad-induced affect, beliefs and attitudes", Journal of Advertising, vol. 35, n. 1, pp. 35-51.

HOMER P.M. (2008), "Perceived quality and image: When all is not "rosy"', Journal of Business Research, vol. 61, n. 7, pp. 715-723.

HSU C.L., LIN J. C.C. (2008), "Acceptance of blog usage: The roles of technology acceptance, social influence and knowledge sharing motivation", Information and Management, vol. 45, n. 1, pp. 65-74.

JOHNSON T.J., KAYE B.K. (2004), "Wag the blog: How reliance on traditional media and the Internet influence credibility perceptions of weblogs among blog users", Journalism and Mass Communication Quarterly, vol. 81, n. 3, pp. 622-642.

JOHNSON T.J., KAYE B.K. (2009), "In blog we trust? Deciphering credibility of components of the internet among politically interested internet users", Computers in Human Behavior, vol. 25, n. 1, pp. 175-182.

KAPLAN D. (2009), Structural equation modeling: Foundations and extensions, Sage, Thousand Oaks, CA.

KATZ-GERRO T. (2011), "Cross-national cultural consumption research: inspirations and disillusions", Kölner Zeitschrift für Soziologie und Sozialpsychologie, vol. 51, pp. 339-360.

KULMALA M., MESIRANTA N., TUOMINEN P. (2013), "Organic and amplified eWOM in consumer fashion blogs", Journal of Fashion Marketing and Management: An International Journal, vol. 17, n. 1, pp. 20-37.

LI F., ZHOU N., KASHYAP R., YANG Z. (2008), "Brand trust as a second-order factor", International Journal of Market Research, vol. 50, n. 6, pp. 817-839.

LU H., LIN J.C.C. (2002), "Predicting customer behavior in the market-space: a study of Rayport and Sviokla's framework", Information and Management, vol. 40, n. 1, pp. 1-10.

MARKUSEN A., WASSALL G. H., DENATALE D., COHEN R. (2008), "Defining the creative economy: Industry and occupational approaches", Economic Development Quarterly, vol. 22, n. 1, pp. 24-45.

NOBLE S.M., GRIFFITH D.A., WEINBERGER M.G. (2005), "Consumer derived utilitarian value and channel utilization in a multi-channel retail context", Journal of Business Research, vol. 58, n. 12, pp. 1643-1651.

OVERBY J.W., LEE E.J. (2006), "The effects of utilitarian and hedonic online shopping value on consumer preference and intentions", Journal of Business Research, vol. 59, n. 10, pp. 1160-1166.

PARK B., AHN S., KIM H. (2010), "Blogging: mediating impacts of flow on motivational behavior", Journal of Research in Interactive Marketing, vol. 4, n. 1, pp. 6-29.

PELTONIEMI M. (2015), "Cultural Industries: Product-Market Characteristics, Management Challenges and Industry Dynamics", International Journal of Management Reviews, vol. 17, n. 1, pp. 41-68.

POOKULANGARA S., HAWLEY J., XIAO G. (2011), "Explaining consumers' channel-switching behavior using the theory of planned behavior", Journal of Retailing and Consumer Services, vol. 18, n. 4, pp. 311-321.

PORNPITAKPAN C. (2004), "The persuasiveness of source credibility: A critical review of five decades' evidence", Journal of Applied Social Psychology, vol. 34, n. 2, pp. 243-281. 
PÖYRY E., PARVINEN P., MALMIVAARA T. (2013). "Can we get from liking to buying? Behavioral differences in hedonic and utilitarian Facebook usage", Electronic Commerce Research and Applications, vol. 12, n. 4, pp. 224-235.

PREMKUMAR G., RAMAMURTHY K., LIU H.N. (2008), "Internet messaging: An examination of the impact of attitudinal, normative, and control belief systems", Information and Management, vol. 45, n. 7, pp. 451-457.

RISPOLI M., TAMMA M. (1992), "Beni e servizi, cioè prodotti”, Sinergie, n. 29, pp. 95-113.

SHIAU W.L., LUO M.M. (2013), "Continuance intention of blog users: the impact of perceived enjoyment, habit, user involvement and blogging time", Behaviour and Information Technology, vol. 32, n. 6, pp. 570-583.

SOLIMA L. (2008), "Visitatore, cliente, utilizzatore: nuovi profili di domanda museale e nuove traiettorie di ricerca", in Bollo A. (Ed.) I pubblici dei musei. Conoscenza e politiche, Franco Angeli, Milano.

SOLIMA L. (2010), "Social Network: verso un nuovo paradigma per la valorizzazione della domanda culturale", Sinergie, n. 82, pp. 42-74.

SOOKEUN B., FEINBERG R.A. (2007), "Understanding consumer acceptance of mobile technology for financial service delivery", AMA Winter Educator's Conference Proceedings, vol. 18, pp. 81-82.

STIGLER G.J. BECKER G.S. (1977), "De gustibus non est disputandum”, The American Economic Review, vol. 67, n. 2, pp. 76-90.

SWEETSER K.D., METZGAR E. (2007), "Communicating during crisis: Use of blogs as a relationship management tool", Public Relations Review, vol. 33, n. 3, pp. 340-342.

THROSBY D. (1994), "The production and consumption of the arts: a view of cultural economics", Journal of Economic Literature, vol. 32, n. 1, pp. 1-29.

VOSS K.E., SPANGENBERG E.R., GROHMANN B. (2003), "Measuring the hedonic and utilitarian dimensions of consumer attitude", Journal of Marketing Research, vol. 40, n. 3, pp. 310-320.

\section{Academic or professional position and contacts}

\section{Francesca Magno \\ Researcher Fellow of Management \\ University of Bergamo - Italy \\ e-mail: francesca.magno@unibg.it}

\section{Cristina Bettinelli}

Researcher of Management

University of Bergamo - Italy

e-mail: cristina.bettinelli@unibg.it

\section{Mara Bergamaschi}

Associate Professor of Management

University of Bergamo - Italy

e-mail:mara.bergamaschi@unibg.it
Francesca Magno Cristina Bettinelli

Mara Bergamaschi

The contribution of Italian cultural blogs to heritage valorization 